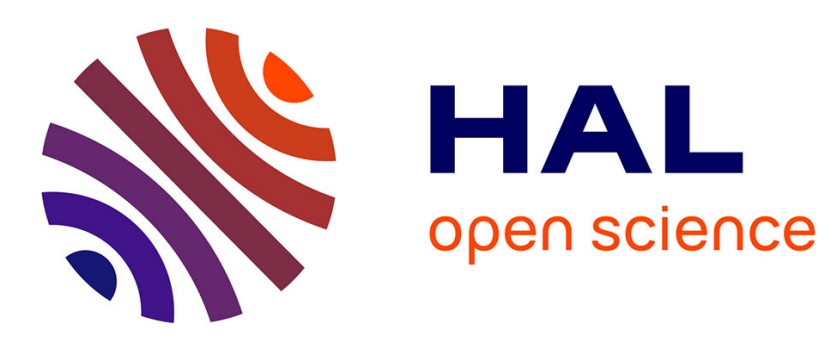

\title{
Cognitive and Emotional Interaction
}

Amel Achour, Jeanne Villaneau, Dominique Duhaut

\section{To cite this version:}

Amel Achour, Jeanne Villaneau, Dominique Duhaut. Cognitive and Emotional Interaction. Sojka, Petr and Horák, Aleš and Kopecek, Ivan and Pala, Karel. Text, Speech and Dialogue, Springer Berlin / Heidelberg, pp.553-560, 2008, 10.1007/978-3-540-87391-4_70 . hal-00515228

\section{HAL Id: hal-00515228 https://hal.science/hal-00515228}

Submitted on 6 Sep 2010

HAL is a multi-disciplinary open access archive for the deposit and dissemination of scientific research documents, whether they are published or not. The documents may come from teaching and research institutions in France or abroad, or from public or private research centers.
L'archive ouverte pluridisciplinaire HAL, est destinée au dépôt et à la diffusion de documents scientifiques de niveau recherche, publiés ou non, émanant des établissements d'enseignement et de recherche français ou étrangers, des laboratoires publics ou privés. 


\title{
Cognitive and emotional interaction
}

\author{
Amel Achour, Jeanne Villaneau, and Dominique Duhaut \\ Valoria, Université de Bretagne Sud, Lorient-Vannes \\ Centre de recherche de Saint Maudé, 56100 Lorient, France \\ \{amel.achour, jeanne.villaneau, dominique.duhaut\}@univ-ubs.fr \\ http://www. univ-ubs.fr
}

\begin{abstract}
The ANR project EmotiRob aims at conceiving and realizing a companion robot which interacts emotionally with fragile children. However, the project MAPH which is an extension of EmotiRob tries to extend the cognitive abilities of the robot to implement a linguistic interaction with the child. For this, we studied a children corpus and got semantic links that could exist between each pair of words. This corpus elaborated by D. Bassano has been used to evaluate language development among children under five. Using this corpus, we tried to make a taxonomy in accordance with the conceptual world of children and tested its validity. Using the taxonomy and the semantic properties that we attributed to the corpus words, we defined rapprochement coefficients between words in order to generate new sentences, answer the child questions and play with him. As a perspective for this, we envisage to make the robot able of enriching its vocabulary, and to define new learning patterns basing on its reactions.
\end{abstract}

Key words: Cognitive interaction, emotion, corpus, taxonomy, semantic links, child conceptual world

\section{Introduction}

A new important field of study in robotics is the domain of companion robots which execute complex tasks and offer behavior enrichment through their interaction with human beings. The French project, EmotiRob, supported by the ANR (National Agency of Research), belongs to this research domain and aims at conceiving and realizing a "reactive" autonomous soft toy robot, which can interact emotionally with children weakened by disease, and bring them some comfort. Previous experiments have already shown the contribution of companion robots in this type of situation $[6,5]$.

The research presented here corresponds to a part of the MAPH project (Active Media for the Handicap) which is related to the EmotiRob project. It aims at extending the robot's reaction capacities so that it could maintain a natural-language "conversation" with the child. The purpose of this work, indeed, is to build a linguistic and cognitive interaction module between the child and the robot by the generation of new subjects and sentences, and by the implementation of well-targeted games. 
A recognition/comprehension module of the child's words supplies the cognitive interaction module inputs; this module of recognition/comprehension is the subject of another study within the EmotiRob project. The recognition of the child words is done using DRAGON software which is a commercial product developed by NUANCE. The sentences generated by the robot depend on the emotional states of both robot and child. The basic tool of the cognitive interaction module is a corpus established by means of the DLPF tool which was realized by D. Bassano, F. Labrell, C. Champaud, F. Lemétayer and P. Bonnet [1]. This tool is an instrument intended to estimate the development of production language of French children whose age is between two and five. This corpus counts a little less than 1500 words including nouns, verbs, adjectives, adverbs, onomatopoeias and common expressions, articles and pronouns among which we find all the common vocabulary that could be said by a 4 -year-old child. The problem which arises is then how to model the conceptual world of a very young child. We thus thought of conducting some surveys in elementary classes in order to find how children at an early age see their surroundings. By studying the semantic relations which could exist between the different words of the corpus, we established a classification of the words or rather taxonomy according to not only objective but also emotional properties.

In order to give our system robustness, we plan for corpus enrichment, as well as the addition of new knowledge. So that, the system must be capable of semantically connecting the new words added to those already in its base of knowledge and to draw up their lists of properties.

In the following section, we will give a small outline on what has already been done in the field of language treatment and robotics dedicated to children. Then, we will detail our approach and the work that we have done. First of all, we are going to describe the taxonomy which we created then the method used in the calculation of semantic links between the corpus words. Then, we will describe how we used this taxonomy in the generation of sentences and speech as well as games between child and robot, and how we plan to continue this work.

\section{Related works}

Carrying on a "natural" conversation with a machine on a non constrained subject seems to be very difficult and even impossible [8] as we cannot model world knowledge right now. By restricting the field of the conversation and choosing a well-defined subject, the use of natural language in order to carry a "dialogue" becomes feasible but still very difficult. Some existing systems of human-machine dialogue that we can quote here are COALA ${ }^{1}$ which is a system for documentary assistance in a town media library, CMU Communicator ${ }^{2}$ which is realized by Carnegie Mellon University, and serves as a tourist guide. Problems that come up against the conception and the realization of human-machine dialogue systems are essentially oral language recognition and understanding [7], real time

\footnotetext{
${ }^{1}$ http://www-ic2.univ-lemans.fr/ lemeunie/these/node35.html

2 http://www.speech.cs.cmu.edu/Communicator/
} 
conversation constraint and finally, speaking with the machine must not require learning from the user [9]. Regarding our project, we are implementing a generic human-machine dialogue system dedicated to young children. We are dealing with vocabulary covering the child's entire surroundings. This is quite problematic as we have a non-restricted conversation domain. However, limiting the users of our system to young children makes the vocabulary we are interested in quite restricted. Moreover, despite the fact that we conceived different types of interactions, they are still well targeted. Under these conditions, producing a dialogue between the child and the robot is conceivable. In our case, we are working with a limited corpus of children whose age is under five, in order to carry on cognitive interaction with the robot. This interaction should also depend on the child's perception of the world and his/her emotional state. In spite of the important interest of emotions in generating a realistic dialogue $[3,4]$, this concerned only dialogues between adults and ignored children. As far as corpus study and computing of semantic links between words are concerned, the works that we found are generally statistic methods applied to large corpus of words. The purpose of such systems is essentially improving the automatic extraction of knowledge, as well as documentary search. As we have already said, our objective is to imagine an ontology of the world as it is viewed by children not only regarding its cognitive aspects, but also regarding its emotional ones. We also aim at being in accordance with their way of thinking and their perception of things. That is why we tried to validate our research with children and to verify if we have satisfied these constraints. From the beginning, we opted for the development of a prototype of the system which will evolve throughout our work in order to satisfy our various specifications and requirements. In the following section, we are going to describe the approach used during this work.

\section{Classification of the corpus words and creation of the taxonomy}

\subsection{Creation of the taxonomy}

In order to calculate the coefficients of semantic link between pairs of words, we began by classifying all the words of the corpus in various classes according to their senses. At the first level we find the verbs, the adjectives and the common nouns. Each of these three classes was afterward divided into several categories, which gave place to numerous sub-categories with a more specific sense of words, and so on. The figure below shows a small outline of the taxonomy that we obtained. The detail of the taxonomy is visible on the site of EmotiRob ${ }^{3}$.

\subsection{Validation of the taxonomy with the children}

To validate the word taxonomy that we created, we thought of making a questionnaire and having children, between 5 and 7 years old, fill it out. According

${ }^{3}$ http://www-valoria.univ-ubs.fr/emotirob/ 


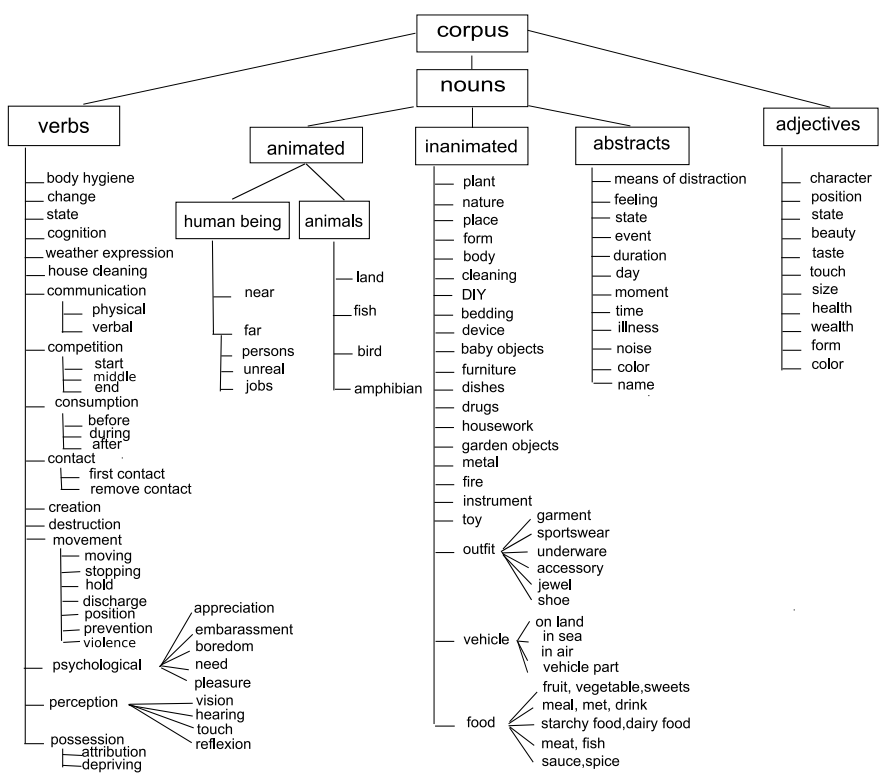

Fig. 1. Taxonomy of children words

to Piaget [2] the children of lower age tend to fantasize and to say anything when they do not know the answer to the question or even when they are not sure of the answer. It is what Piaget calls the "whateverism" phenomenon. To implement the various questions and parts of the questionnaire, we used the tests method, which is often employed on the study of the childish beliefs. This method requires two essential conditions: the first one demands that questions should be the same for all the subjects and asked in the same circumstances. The second condition requires that all the answers must be reported to the same evaluation scale. This method has the advantage of giving useful information statically speaking; however, the risk of falsifying the child spirit orientation remains important. To remedy this problem, it is necessary to vary the questions and to make counter-suggestions. Thus, in our questionnaire we opted for various types of questions such as questions with multiple choices, tables to fill out, as well as searching for adequate solutions among a set of possible ones.

This questionnaire essentially concerns the animated beings that surround the children: human or animal, and with whom they can have more or less emotional links. The first part of the questionnaire was dedicated to human beings. At first, we asked the children to distinguish the characters we find around us from those who exist only in tales. And second, we tried to find the different primary feelings which evoke these characters in their minds.

The second part was dedicated to animals and aimed at verifying their belonging to the different categories established in the taxonomy. The questionnaire was filled in by first-grade pupils from "Sainte Marie" elementary school in Lori- 
ent twice. After the counting of the answers, we noticed that, in the majority of the cases, the results are in accordance with the taxonomy and answer, indeed, our expectations. Nevertheless, certain results surprised us and made us modify the taxonomy. For example, according to $92 \%$ of the questioned children, "king" and "prince" characters do not exist in the real world and are only in tales and stories we tell them. "Father Christmas" belongs to the set of imaginary characters for only the half of the children, the other half consider him as a real person. $80 \%$ of children are "happy" when they see a "magician" and consider him as a "kind person". To many children, almost half, an "ostrich" and a "penguin" are not birds, and nearly $70 \%$ of them think that a "whale" is a fish.

\section{Calculation of rapprochement coefficients}

According to the taxonomy, we tried to measure the semantic links which exist between the words. For that purpose, we defined rapprochement coefficients between pairs of words. In the next part, we describe these rapprochement coefficients, as well as the method used for calculation.

\subsection{Rapprochement between two common nouns}

The set of common nouns was divided into three big classes, the class of animate, inanimate and abstracts. Each of these classes was afterward divided in several sub-categories, and so on. Here is the formula used to calculate the rapprochement Rapproch ( N1,N2) between two common nouns N1 and N2:

$$
\operatorname{Rapproch}(N 1, N 2)=\frac{C 1 * R 1(N 1, N 2)+C 2 * R 2(N 1, N 2)}{C 1+C 2}
$$

As can be noticed, the rapprochement coefficient between two common nouns is a weighted average between two coefficients, the first of which, R1(N1,N2), calculates the rapprochement between both words in the taxonomy, whereas the second evaluates their rapprochement regarding to their common properties number. We distinguished two types of properties: affective properties and objective ones. Each property was balanced with a weight measuring its importance in defining a certain set of words. $\mathrm{R} 2$ is then the weighted average of an affective rapprochement $\operatorname{Raff}(N 1, N 2)$ weighted by an affective coefficient $Q a$, and an objective rapprochement $\operatorname{Robj}(N 1, N 2)$ weighted by an objective coefficient $Q o$.

$$
\begin{aligned}
\operatorname{Raff}(N 1, N 2) & =\frac{n b r \_p r o p \_a f f \_c o m(N 1, N 2)}{\max \left(n b r \_p r o p \_a f f(N 1), n b r \_p r o p \_a f f(N 2)\right)} \\
R o b j(N 1, N 2) & =\frac{n b r \_p r o p \_o b j \_c o m(N 1, N 2)}{\max \left(n b r \_p r o p_{-} o b j(N 1), n b r \_p r o p \_o b j(N 2)\right)} \\
R 2(N 1, N 2) & =\frac{Q a * R a f f(N 1, N 2)+Q o * R o b j(N 1, N 2)}{Q a+Q o}
\end{aligned}
$$


The rapprochement coefficients we obtained depend on the $Q a$ and $Q o$ that we chose. For instance, "ladybug" and "louse" will be semantically close if Qo is bigger than $Q a$. Otherwise, they will be distant.

\subsection{Rapprochement between two verbs}

To describe the semantic rapprochement between any two verbs, we defined two types of coefficients. The first one calculates the rapprochement between both verbs with regard to their place in the taxonomy. The second coefficient is calculated according to their respective types (intransitive, transitive or double transitive) and according to the taxonomic rapprochement between their subjects and respective complements. So, the rapprochement coefficient between two verbs is a weighted average of both coefficients calculated previously.

\subsection{Rapprochement between two adjectives}

The calculation of the rapprochement coefficient between two adjectives bases on the preliminary calculation of two rapprochement coefficients. The first one is calculated with regard to the properties described by adjectives (size, shape, taste, etc.). So, it represents their rapprochement in the taxonomy. As for the second coefficient, it is calculated according to the types of subjects that can be applied to both adjectives. The rapprochement coefficient between two adjectives is then a weighted average of these two coefficients.

\subsection{Rapprochement between verb and noun, adjective and noun}

We defined the rapprochement coefficient between noun and verb to measure the applicability of some verbs to a particular noun. For example, we can say that the verb "to bore" applies perfectly to an animate subject whereas if the same verb can be applied to a "chair", that is possible only in an artistic or a funny context. Also for adjectives, the rapprochement coefficient between noun and adjective measures rather the use of an adjective with a certain name in a particular speech context.

\section{Sentence generation and maintenance of the child-robot speech}

The sentence generation model that we adopted works with simple input sentences such as (subject, adjective), (subject, intransitive verb), (subject, transitive verb, complement) or (subject, verb double transitive, complement1, complement2). At the present time, we have limited our choice to one type of sentence which is the affirmative sentences. Later, we intend to work on the acts of language and to introduce the interrogative, imperative sentences, etc.

The generation module takes several parameters into account which describe the emotional state of the child, as well as the humor of the robot. First of 
all, it analyzes the input sentence so as to find the context that the speech is about. Secondly, it looks for words which represent a certain value of the semantic rapprochement coefficients with the words composing the input sentence. Several cases are possible, according to the speech context (realistic, funny, artistic, etc.) and according to the emotional states of both the child and the robot. The robot will then be able to answer the child either by keeping the same subject of discussion or a similar one, or by approaching another completely different subject.

\subsection{Child-robot interactive games}

Because of the playful and psychological interest of games for children, we considered it very interesting to introduce a game module in order to distract the child and maximize his comfort. As an example of game, we thought of a simple play on words where the second opponent should formulate a sentence which begins with the last word pronounced by the first opponent or to keep some words of the input sentence and to change the others while ensuring a coherent meaning to the sentence. In another game, the child asks the robot to guess something from certain properties that he would give him as indications. For that purpose, we defined a certain number of prototypes related to what we think belong to the conceptual world of children. Each of these prototypes is described by a certain number of properties. An example of such a prototype is "pet" which can be described by the following list of properties, present in our taxonomy: (it lives in the house, it is sweet, you play with it, etc.) or also the prototype "bird" which can be defined as: (it has feathers, it has a beak, it lays eggs, it has wings, it flies, etc.).

We have now implemented a classic riddle game in which the child begins by choosing an animal and on the other hand, the robot tries to guess it by asking a series of questions. The questions asked essentially concern the classification of animals described in the taxonomy. The robot adopts a strategy concerning the choice of the questions which essentially depends on the child's answers and which can change during the game. However, what increases the interest of the game is that the robot can know if the child made a mistake in answering one of his questions or if he cheated on purpose. By checking all the answers supplied by the child, the robot can thus protest if the child gave him a bad answer. As the robot will be endowed with an internal humor, its reaction can be declined according to several modes: annoyed, amused or simply neutral.

\section{Conclusion and perspectives}

The system that we have developed allows both cognitive and emotional communication and interaction between the child and the robot. It aims at the entertainment of the child by putting him in front of a companion capable of oral interaction and endowed with cognitive and linguistic capacities. Our future work will now focus on finding other types of interactions and new series 
of games. As we have already said, one of the capacities with which we want to endow our system is to be able to enrich its vocabulary: new words can be added to the taxonomy and be bound semantically and in an automatic way to what already exists in the system knowledge database. We are currently thinking about the way we will allow the system to evolve. We also intend to define learning frameworks; according to the answers the system is going to produce, to adapt it to our expectations and to those of the children. The evaluation of our work is rather delicate because it involves child psychology. We thus have to foresee evaluation methods which allow for the measuring of the quality of the interaction between the robot and the child and the comfort brought to him. More simply, we thought of elaborating a questionnaire which should be filled in by voluntary adults and children in order to test their reactions face to face with the robot, and to see what they think of games and of the quality of the robot reactions.

Acknowledgments. We thank the region of Brittany for the interest and the support which it brings to the project. We also wish to thank Dominique Bassano for her collaboration by giving us access to her child corpus. //This rich and interesting corp

\section{References}

1. D. Bassano, F. labrell, C. Champaud, F. Lemétayer, P. Bonnet: Le DLPF: un nouvel outil pour lévaluation du développement du langage de production en franais. Enfance, 2, 171-208 (2005)

2. J. Piaget: La représentation du monde chez l'enfant. Presses universitaires de France (1947)

3. D. Keltner, J. Haidt: Social functions of emotions. In: T. Mayne and G. A. Bonanno (eds.), Emotions: Current issues and future directions. pp. 192-213, Guilford Press, New York (2001)

4. C. Adam, F. Evrard: Donner des émotions aux agents conversationnels. Workshop Francophone sur les Agents Conversationnels Animés, pp. 135-144, Grenoble, France (2005)

5. T. Shibata: An overview of human interactive robots for psychological enrichment. In: Proceedings of the IEEE, vol. 92, NO. 11, pp. 1749-1758 (2004)

6. K. Wada, T. Shibata, T. Saito, K. Tanie: Effects of Robot-Assisted activity for elderly people and nurse at day service center. In: Proceedings of the IEEE, vol. 92, NO. 11, vol. 92,pp. 1780-1788 (2004)

7. J. Glass: Challenges for spoken Dialogue Systems. pp. 39-61, IEEE ASRU Workshop, KeyStone, Colorado, USA (1999)

8. Y. Wilks, R. Catizone: Encyclopedia of Microcomputers, chap. Human-Computer Conversation. Dekker, New York (2000)

9. G. Gazdar: The simulation of Human intelligence, chap. The handling of natural language. pp. 150-177, Donald Broadbent edition, Blackwell, Oxford (1993) 